\title{
Heat transfer properties of post-medieval crucibles
}

(published in Archaeological and Anthropological Sciences 2018,

DOI https://doi.org/10.1007/s12520-018-0669-8)

Anno Hein ${ }^{1}$, Vassilis Kilikoglou ${ }^{1}$ and Marcos Martinón-Torres ${ }^{2}$

${ }^{1}$ Institute of Nanoscience and Nanotechnology, N.C.S.R. “Demokritos”, 15310 Aghia Paraskevi, Attica, Greece

${ }^{2}$ McDonald Institute for Archaeological Research, University of Cambridge, Downing Street, Cambridge, CB2 3ER, United Kingdom

\begin{abstract}
In the present case study the thermal conductivity of two post-medieval crucibles was determined. The investigated crucible fragments represented two broadly contemporary production sites, Großalmerode and Obernzell, which were employing different types of raw materials (sand tempered kaolinitic clays and natural graphitic clays, respectively) and different firing conditions. The samples were part of a larger assemblage, which had been studied in view of production technology and function of pyrotechnical ceramics in post-medieval Europe and in view of dissemination of products from different production centres. The study results were expected to provide complementary information regarding the technology and use of the crucibles.
\end{abstract}

\section{Keywords}

crucibles, post-medieval, mullite, graphite, heat transfer, thermal conductivity

\section{Introduction}

Thermo-mechanical properties of pyrotechnical ceramics have a paramount impact on their use and operational conditions. Their refractoriness, i.e. inertness and mechanical performance at extreme temperatures, as well as the heat transfer through the ceramic walls are constraints for their function and their feasibility to be used in specific pyrotechnical processes. The knowledge and availability of raw materials have played a major part in technological developments in the past, for example the adoption of kaolinitic clays for crucible production from the Roman period onwards, which afforded more temperature-resistant crucibles (Freestone 1989; Martinón-Torres and Rehren 2014). Eventually, it was possible to fabricate effectively refractory ceramics, which could withstand temperatures necessary for pyrotechnical processes. Their refractoriness and toughness made it possible to manufacture thin-walled crucible shapes, which could be heated from outside. As a result of this, efficient heat transfer through the crucible walls was beneficial. Prior to that, crucibles with comparably thick walls had to be used, which were heated from inside or above with the internal surface commonly distorting at the temperatures prevailing during the pyrotechnical process (Freestone 1989). Due to this different kind of operation the suppression of heat transfer through the crucible walls was preferred, commonly achieved by a porous ceramic matrix generated by tempering the clay with organic fibres (Bayley and Rehren 2007; Hein et al. 2013). 
In the present case study two specimens of early modern crucibles of the 'triangular' laboratory type were investigated for their thermal conductivity: one from Großalmerode (Hesse) and one from Obernzell (Bavaria), which are known as the main crucible-pruducing regions in the post-medieval world (Martinón-Torres and Rehren 2009). Both of the crucibles were recovered in the production regions and were used as references for provenance purposes. Triangular crucibles present a characteristic shape with three pouring spouts, achieved by pushing inwards the rim of a vessel prior to firing (Figure 1).The crucibles were part of a large-scale study on post-medieval crucibles characterizing the crucible ware types of specific production sites and investigating their performance and dissemination (Martinón-Torres and Rehren 2009). In spite of their different raw materials and manufacturing techniques, both crucible ware types displayed very good material properties and performance, and as such they were very successful and exported internationally. The Hessian crucibles from Großalmerode were produced from kaolinitic clays, tempered with quartz sand (20-40\%) and pre-fired at temperatures of typically $1300^{\circ} \mathrm{C}$ (Martinón-Torres et al. 2008). Remarkable is also the low iron oxide content not exceeding $2 \mathrm{wt} \%$ (Martinón-Torres and Rehren 2009). The ceramic matrix of the non-used crucibles showed continuous to total vitrification with cristobalite and mullite developing as high temperature phases (Martinón-Torres et al. 2006, 2008). The crucibles from Obernzell, on the other hand, were produced from graphitic clays, with a graphite content of commonly above $40 \%$, and they were pre-fired at comparably lower temperatures, estimated around $950-1050{ }^{\circ} \mathrm{C}$ based on the observed initial to intermediate degree of vitrification, together with the unaltered state of potassium feldspar inclusions in non-used vessels (Martinón-Torres and Rehren 2009). The ceramics showed also clearly higher iron oxide levels (exceeding $7 \mathrm{wt} \%$ ) and lower alumina compared to the Hessian crucibles indicating potentially lower refractoriness, which could however be compensated for by the graphite inclusions. As such, both types of ceramic fabrics had been described by Martinón-Torres and Rehren (2009) as suitably refractory to cope with the thermal, chemical and mechanical stresses involved in a variety of metallurgical and chemical operations. Although both crucible types are therefore of good material properties overall, the fact that two different recipes had been systematically used in each region, and that both appeared distributed internationally, raised the possibility that the choice between them might in some cases be driven by specific performance characteristics (Martinón-Torres and Rehren 2009). In this case study, we investigated the heat transfer of both crucible fabrics, with the expectation that their thermal conductivities would be considerably higher than those of of preRoman pyrotechnical ceramics such as Late Bronze Age crucibles or smelting furnaces (Hein et al. 2013).

\section{Experimental approach}

The thermal conductivity of the crucibles was determined with a steady state hot disk set-up (Hein et al. 2013). For this, ceramic disks with a diameter of c. $52 \mathrm{~mm}$ (Großalmerode) and c. $60 \mathrm{~mm}$ (Obernzell) were cut out of the two crucible fragment bases and polished in order to have suitably flat and parallel surfaces. The polished disks had thicknesses of $8.6 \mathrm{~mm}$ and $12.7 \mathrm{~mm}$, respectively. On the basis of the dimensions of the disks and their dry weight, the apparent densities of the two crucible materials were estimated. For the measurement the particular sample disk was placed on a heating plate with stabilized and monitored temperature. The top side of the sample was in contact with a second thermally conductive brass disk. The temperature increase in the thermal conductor was measured until equilibrium was reached, in terms of a stable temperature difference $d T=T_{0}-$ $\mathrm{T}_{\text {surf }}$ between heating plate and conductor disk. In equilibrium the heat flux through the ceramic disk 
corresponded essentially to the heat dissipated by the thermal conductor into the environment. This heat depended predominantly on the temperature of the disk and had been estimated in an independent measurement. On the basis of the measured temperature difference, respective disk dimensions and estimated heat flux the thermal conductivity of the ceramics was determined. The present estimations of the thermal conductivity are based on four independent series of measurements of each disk in a temperature range of the heating plate of 120 to $370{ }^{\circ} \mathrm{C}$ in order to assess the temperature dependence of the heat transfer.

In order to study the ceramic fabrics and particularly the characteristic inclusions, polished sections of the two crucibles were prepared and investigated under a FEI, Quanta Inspect D8334 scanning electron microscope (SEM). Series of micrographs in backscattering mode were evaluated with image processing towards the estimation of the porosities of the two ceramic fabrics using the open source ImageJ software (imagej.net). Due to the minimum pixel size of the evaluated micrographs pores only with sizes of above c. $5 \mu \mathrm{m}$ were considered.

\section{Results and discussion}

In earlier case studies the density of ceramic materials had proven to be a decisive parameter for thermal conductivity (Hein et al. 2013). The sand tempered crucible from Großalmerode presented indeed a considerably higher apparent density of $2.01 \mathrm{~g} / \mathrm{cm}^{3}$ than the crucible from Obernzell , which with $1.75 \mathrm{~g} / \mathrm{cm}^{3}$ resembled rather the density of porous pre-historic crucibles or smelting furnaces (Table 1). However, SEM micrographs taken from the two investigated crucibles indicated that neither of the two fabrics was particularly porous. The porosity of the crucible from Großalmerode (Figure 2) was estimated at $11.5 \pm 2$ vol\% and the porosity of the crucible from Obernzell (Figure 3) at $2.5 \pm 1$ vol\%. Thus, the different apparent density was related rather due to the lower density of the graphite inclusions in the ceramic matrix of the crucible from Obernzell compared to the quartz inclusions in the ceramic matrix of the crucible from Großalmerode.

The estimated thermal conductivity indicated a considerable difference between the two crucible fabrics, with the crucible sample from Obernzell presenting a thermal conductivity over twice as high as the sample from Großalmerode (Table 1). This could not have been expected solely from the apparent density, which would have suggested actually the opposite, as in the case of porous prehistoric pyrotechnical ceramics (Table 1) (Hein et al. 2013). The explanation for the increased thermal conductivity is most probably the presence of thermally highly conductive graphite in the matrix (Figure 3) as it had been already presumed by Martinón-Torres and Rehren (2009).

Furthermore, in the case of the sand tempered crucibles from Großalmerode, SEM micrographs had indicated that due to the thermal expansion of the quartz inclusions, microcracks had developed at their boundaries and sequentially between the inclusions, which could be expected to suppress heat transfer (Figure 2). Recent measurements of a kaolinitic clay fired at different temperatures indicated actually potentially higher thermal conductivities achievable for pre-fired crucibles of this clay type (Table 1) (Allegretta et al. 2017). On the other hand the pore structure related to the quartz tempering was expected to improve the toughness of the ceramics (Kilikoglou et al. 1998).

Finally, a considerable difference in terms of temperature dependence of the estimated thermal conductivity was noted in the measured temperature range of the heat source between $120^{\circ} \mathrm{C}$ and $370^{\circ} \mathrm{C}$. In the case of the graphite bearing crucible a clear decrease of thermal conductivity of almost $20 \%$ was determined while the sand tempered crucible showed an approximately stable thermal 
conductivity in the considered temperature range (Table 1). This was most probably related as well to the thermal conductivity of the graphite inclusions, as graphite presents a decrease of thermal conductivity in this temperature range (Uher 1991).

Apart from thermal conductivity, also refractoriness and thermal shock resistance affected the functionality of the crucibles. In terms of refractoriness both added sand temper as well as naturally present graphite inclusions have presumably sustained sufficiently the ceramic matrix at high temperatures due to their thermal inertness. Thermal shock resistance on the other hand is a complex parameter related to heat conduction, thermal expansion of ceramic matrix and inclusions and mechanical properties, such as strength and toughness. Experiments have shown that high amounts of temper material or natural inclusions, as observed in both investigated ceramic fabrics, increase thermal shock resistance (Müller et al. 2014). Further investigation of the present ceramic fabrics, however, will require additional mechanical testing.

\section{Conclusions}

The assessment of heat transfer in ceramic materials of typical post-medieval crucibles indicated only in the case of crucibles produced from graphitic clays clearly improved heat transfer properties, while the thermal conductivity of sand tempered mullite crucibles appeared to remain rather moderate. However, it has to be considered that also sufficiently thin crucible walls facilitated heat transfer, and indeed mullite Hessian crucibles tend to be thinner than the graphitic crucibles from Bavaria. It is also worth bearing in mind that that on the other hand fast heating involved also fast cooling, which could be a relevant parameter for some reactions. Moreover, heat conduction is only one potential mode of heat transfer and heat radiation inside a furnace or oven has not been considered so far. Thus, further investigations might elucidate whether these two different types of post-medieval crucibles were used under different operation conditions, in terms of heat source and in terms of duration of the specific processes in which they were used. After all, also the mechanical properties of the crucible materials have to be investigated in view of a complete picture of their function and performance.

\section{Bibliography}

Allegretta, I., Eramo, G., Pinto, D. and Hein, A., 2017, The effect of mineralogy, microstructure and firing temperature on the thermal conductivity of traditional hot processing ceramics. Applied Clay Science 135, 260-270.

Bayley, J, and Rehren, Th., 2007, Towards a functional and typological classification of crucibles. In: Metals and Mines (eds. S. LaNiece, D. Hook and P.T. Craddock) 46-55, Studies in Archaeometallurgy, Archetype, British Museum, London.

Freestone, I.C., 1989, Refractory Materials and Their Procurement, in Old World Archaeometallurgy (eds. A. Hauptmann, E. Pernicka, and G.A. Wagner) 155-162, Der Anschnitt Beiheft 7, Deutsches Bergbaumuseum, Bochum.

Hein, A., Karatasios, I., Müller, N.S., and Kilikoglou, V., 2013, Heat transfer properties of pyrotechnical ceramics used in ancient metallurgy, Thermochimica Acta 573, 10, 87-94. 
Kilikoglou, V., Vekinis, G., Maniatis, Y. and Day, P.M., 1998, Mechanical performance of quatztempered ceramics: Part I, strength and toughness, Archaeometry 40, 2, 261-279.

Martinón-Torres, M., and Rehren, Th., 2009, Post-medieval crucible production and distribution: A study of materials and materialities, Archaeometry 51, 1, 49-74.

Martinón-Torres, M., and Rehren, Th., 2014. Technical ceramics, in Archaeometallurgy in Global Perspective (eds. B.J. Roberts and C.P. Thornton) 107-131, Springer, New York.

Martinón-Torres, M., Rehren, Th., and Freestone, I. C., 2006, Mullite and the mystery of Hessian wares, Nature, 444, 437-438.

Martinón-Torres, M., Freestone, I. C., Hunt, A. and Rehren, Th., 2008, Mass-Produced Mullite Crucibles in Medieval Europe: Manufacture and Material Properties, Journal of the American Ceramic Society, 91, 6, 2071-2074.

Müller, N.S., Kilikoglou, V., Day, P.M. and Vekinis, G., 2014, Thermal shock resistance of tempered archaeological ceramics, In Craft and science: International perspectives on archaeological ceramics (ed. M. Martinón-Torres) Bloomsbury Qatar Foundation, Doha.

Uher, C., 1991, Thermal conductivity of pure semimetals and their dilute alloys, in Thermal Conductivity of Pure Metals and Alloys (eds. O. Madelung, G. K. White) 402-448, Springer, Berlin. 


\begin{tabular}{|c|c|c|c|c|c|c|}
\hline & \multirow{2}{*}{$\begin{array}{c}\text { Apparent density } \\
(\mathrm{g} / \mathrm{cm} 3)\end{array}$} & \multicolumn{5}{|c|}{ Thermal conductivity $(\mathrm{W} /(\mathrm{m} \mathrm{K}))$} \\
\hline & & $120^{\circ}$ & $220^{\circ}$ & \multicolumn{2}{|c|}{$320^{\circ}$} & $370^{\circ}$ \\
\hline Großalmerode & 2.01 & $0.82 \pm 0.002$ & $0.80 \pm 0.01$ & 0.78 & \pm 0.005 & $0.77 \pm 0.003$ \\
\hline Obernzell & 1.75 & $2.19 \pm 0.08$ & $2.04 \pm 0.03$ & 1.89 & \pm 0.03 & $1.80 \pm 0.01$ \\
\hline \multicolumn{7}{|c|}{ Late Helladic smelting furnaces (Hein et al. 2013) } \\
\hline Phorades 19 & 1.40 & 0.42 & 0.41 & & .40 & \\
\hline Phorades 20 & 1.19 & 0.31 & 0.32 & & .33 & \\
\hline Phorades 26 & 1.37 & 0.36 & 0.37 & & .38 & \\
\hline Phorades 33 & 1.09 & 0.30 & 0.30 & & .31 & \\
\hline Phorades 36 & 1.47 & 0.43 & 0.43 & & .43 & \\
\hline \multicolumn{7}{|c|}{ Kaolinitic clay (Allegretta et al. 2017) } \\
\hline $950^{\circ} \mathrm{C}$ & 1.94 & 0.58 & 0.59 & & & 0.62 \\
\hline $1050^{\circ} \mathrm{C}$ & 1.97 & 0.90 & 0.86 & & & 0.79 \\
\hline $1150^{\circ} \mathrm{C}$ & 2.00 & 0.59 & 0.62 & & & 0.64 \\
\hline $1250^{\circ} \mathrm{C}$ & 1.98 & 1.20 & 1.15 & & & 1.09 \\
\hline $1350^{\circ} \mathrm{C}$ & 1.99 & 1.07 & 1.02 & & & 0.99 \\
\hline
\end{tabular}

Table 1 - Apparent densities and thermal conductivities of the two crucible samples and comparable ceramic materials: The thermal conductivity of each sample was determined at different temperatures of the heating plate. The experimental error was estimated with repeated measurements at different days. The data of Late Helladic smelting furnaces and of a kaolinitic clay fired at different temperatures were determined with the same setup.

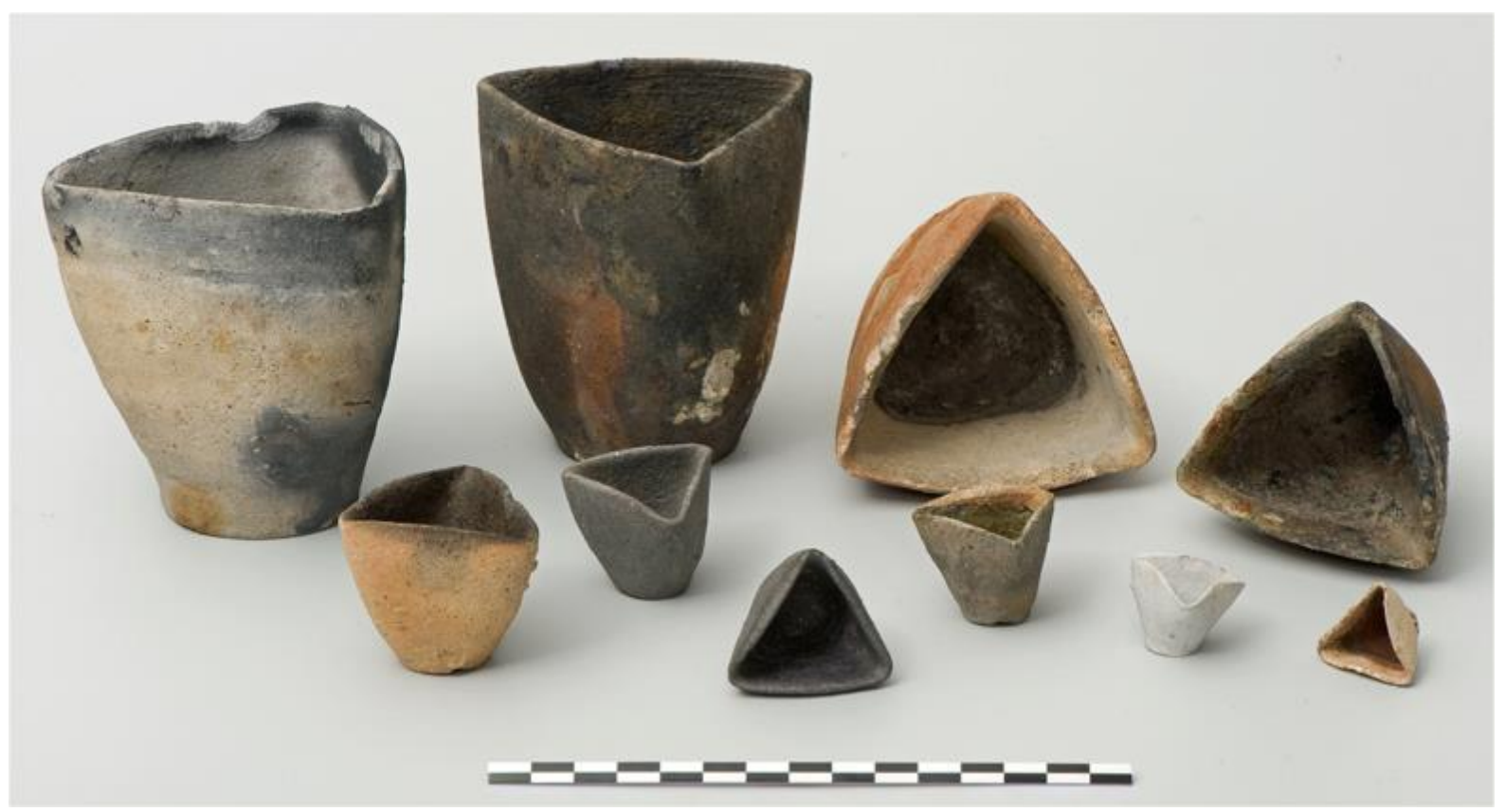

Figure 1 - Example of post-medieval triangular crucibles of different sizes (photo Andreas Rausch). It should be noted that smaller producers outside Hesse and Bavaria made triangular crucibles too, and that beaker-shaped crucibles were produced by all of them. 


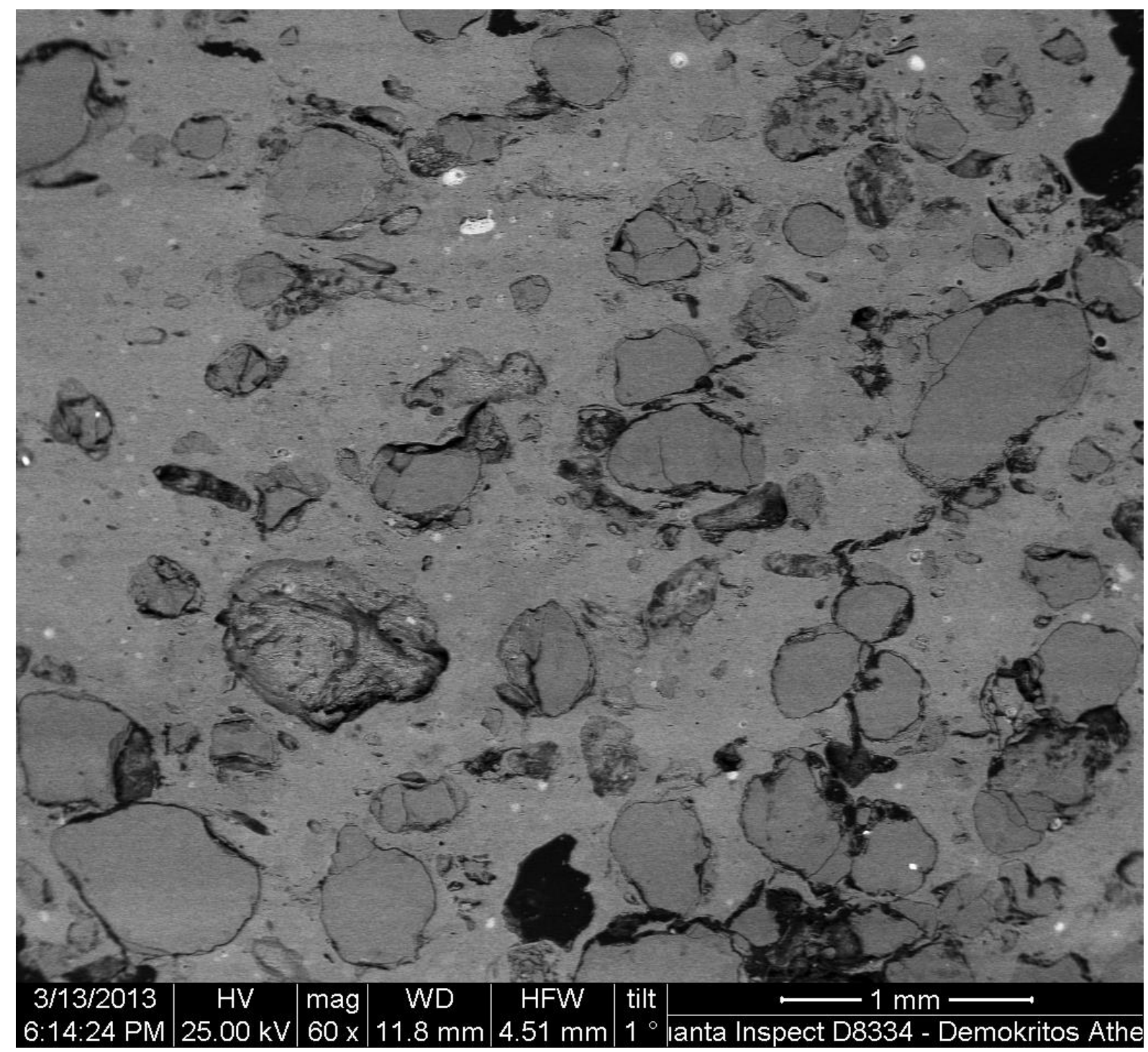

Figure 2 - SEM micrograph in backscattering mode of a polished section of the investigated crucible from Großalmerode: Primary heat flux in the case of operation can be assumed from top to bottom. The ceramic matrix presents frequent sub-rounded or spheroidal quartz inclusions of up to c. $1 \mathrm{~mm}$ in size. Around the quartz inclusions micro-damaged zones can be observed connecting to cracks, which develop between the inclusions. By means of image processing the porosity in the present micrograph can be estimated with c. 10 vol\%. 


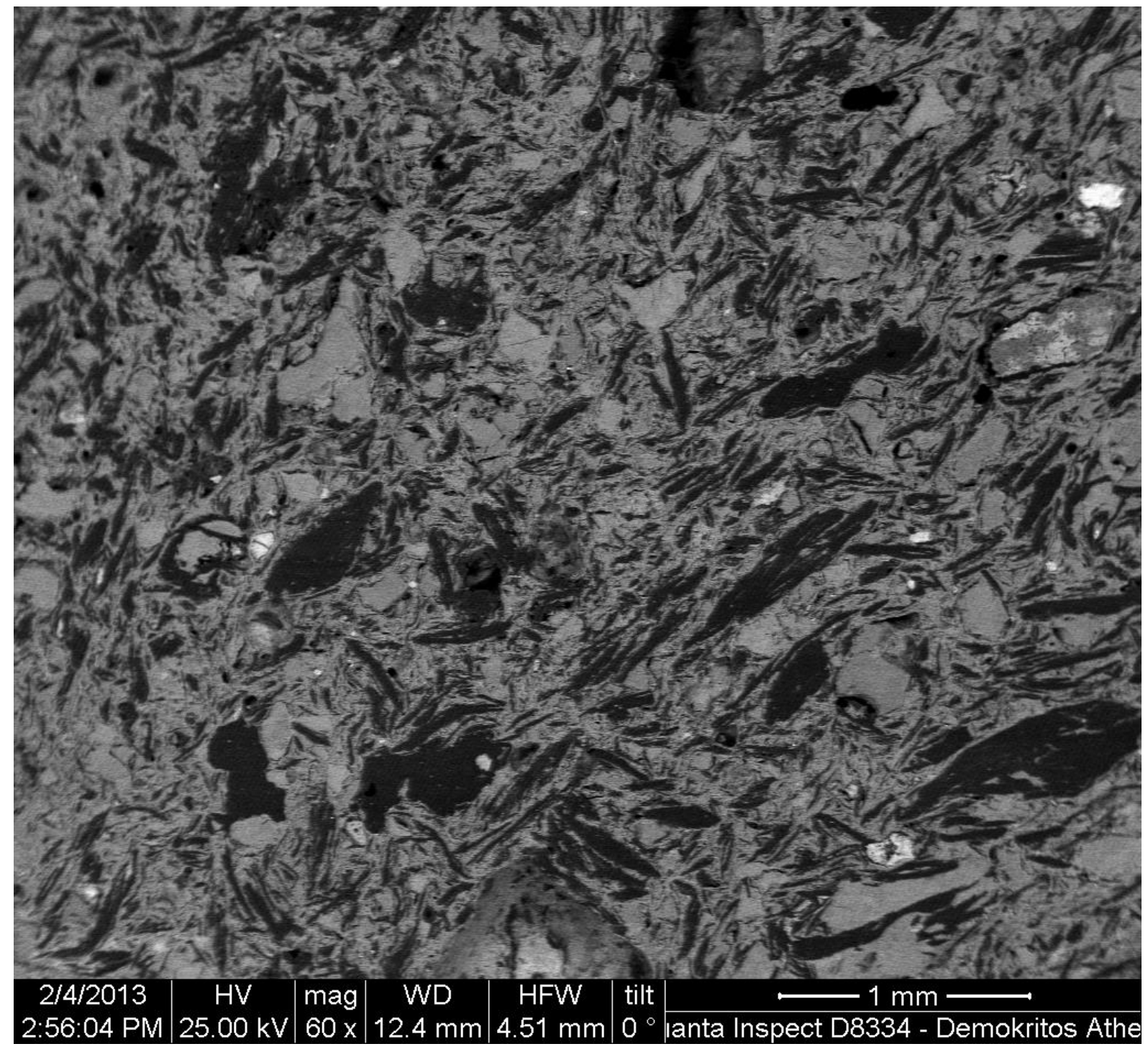

Figure 3 - SEM micrograph in backscattering mode of a polished section of the investigated crucible from Obernzell: Primary heat flux in the case of operation can be assumed from top to bottom. The ceramic matrix presents frequent flaky graphite inclusions with no obvious preference in orientation. By means of image processing the porosity in the present micrograph can be estimated with c. 2 vol\%. 